\title{
Uso de controles e informações gerenciais por empresas startups incubadas
}

\begin{abstract}
Silvana Veroneze
Mestrado em andamento em Administração e Ciências Contábeis pela Universidade Comunitária da Região de Chapecó - UNOCHAPECÓ Administradora na Universidade Federal da Fronteira Sul - UFFS Avenida Brasil 805, Centro. Realeza/PR. CEP 85.770-000. E-mail: silvanaveroneze@gmail.com

Silvana Dalmutt Kruger Doutorado em Contabilidade pela Universidade Federal de Santa Catarina - UFSC Professora do Programa de Mestrado em Ciências Contábeis e Administração da Universidade Comunitária da Região de Chapecó - UNOCHAPECÓ Servidão Anjo da Guarda, 295-D. Efapi. Chapecó/SC. CEP: 89.809-900 E-mail:silvanak@unochapeco.edu.br
\end{abstract}

\section{RESUMO}

O objetivo do estudo é identificar a utilização de instrumentos de controles gerenciais em startups incubadas. A amostra do estudo contempla 13 startups incubadas, metodologicamente a pesquisa é descritiva, realizada por meio de levantamento, com análise de cunho quantitativo. Os resultados evidenciam a intensidade de uso dos instrumentos de sistema controle gerencial, considerando 3 variáveis e 7 subvariáveis, contemplando 44 itens de avaliação. Os achados revelam que a maioria das startups investigadas se concentram nas fases de pré-incubação ou incubação, com evolução dos recursos humanos e financeiros no período de 2017 a 2019. Constatou-se que as variáveis planejamento, avaliação e gestão, possuem maior intensidade de utilização, sendo o plano financeiro com projeções de caixa e prospecção de clientes os mais usuais que utilizam os instrumentos de controle gerencial de forma parcial e circunstancial. No aspecto relacionado aos recursos humanos, observou-se a utilização da remuneração atrelada ao desempenho. As subvariáveis produtos e vendas e as parcerias apresentam menor intensidade de utilização na amostra estudada. De forma geral, espera-se gerar reflexões acerca da importância do uso de instrumentos de controles gerenciais pelas startups, bem como do gerenciamento dos recursos que darão subsídio à tomada de decisões dos gestores dessas organizações.

Palavras-chave: Startups. Empresas incubadas. Inovação.

\section{Use of controls and management information by incubated startups companies}




\section{ABSTRACT}

The objective of the study is to identify the use of management control instruments in incubated startups. The study sample includes 13 incubated startups, methodologically the research is descriptive, carried out by means of a survey, with a quantitative analysis. The results show the intensity of use of the management control system instruments, considering 3 variables and 7 subvariables, comprising 44 evaluation items. The findings reveal that most of the investigated startups concentrate in the preincubation or incubation phases, with an evolution of human and financial resources in the period from 2017 to 2019. It was found that the variables planning, evaluation and management, have greater intensity of utilization, being the financial plan, with cash projections and prospecting for customers the most usual, which use the instruments of management control in a partial and circumstantial way. In the aspect related to human resources, the use of performance-related remuneration was observed. The subvariables products and sales, and partnerships have less intensity of use in the sample studied. In general, it is expected to generate reflections about the importance of the use of management control instruments by startups, as well as the management of resources that support decision-making of the managers of these organizations.

Keywords: Startups. Incubated companies. Innovation.

\section{Uso de los controles y la información de gestión por parte de empresas incubadas}

\section{RESUMEN}

El objetivo del estudio es identificar el uso de instrumentos de control de gestión en startups incubadas. La muestra de estudio incluye 13 startups incubadas, metodológicamente la investigación es descriptiva, realizada mediante encuesta, con análisis cuantitativo. Los resultados muestran la intensidad de uso de los instrumentos del sistema de control de gestión, considerando 3 variables y 7 subvariables, que comprenden 44 ítems de evaluación. Los hallazgos revelan que la mayoría de las startups se concentran en las fases de preincubación o incubación, con la evolución de los recursos humanos y financieros en el período de 2017 a 2019. Se encontró que las variables planificación, evaluación y gestión, tienen mayor intensidad de utilización, siendo el plan financiero, con proyecciones de caja y prospección de clientes el más habitual, que utilizan los instrumentos de control de gestión de forma parcial y circunstancial. En el aspecto relacionado con los recursos humanos, se observó el uso de la remuneración relacionada con el desempeño. Las subvariables productos y ventas y alianzas tienen menor intensidad de uso en la muestra estudiada. En general, se espera generar reflexiones sobre la importancia del uso de instrumentos de control 
de gestión por parte de las startups, así como la gestión de recursos que apoyarán la toma de decisiones de los directivos de estas organizaciones.

Palabras clave: Startups. Empresas incubadas. Innovación.

\section{INTRODUÇÃO}

O surgimento das primeiras empresas denominadas startups de tecnologia nasceram no Vale do Silício na região da Califórnia, EUA, na década de 90 (Brasscom, 2019). No Brasil, o termo começou a ser utilizado entre os anos de 1996 e 2001, na época conhecida como bolha da internet (Sebrae, 2014). Desde então, as startups passaram a ser reconhecidas pela necessidade de inovação ou por se utilizarem de tecnologias (Kohler, 2016; Sebrae, 2014), embora esses negócios não atuem restritamente ao ramo digital (Anprotec, 2019a), abrangem também outras áreas e soluções (Ries, 2012a) e independem de tamanho e setor econômico (Kohler, 2016).

Uma startup pode ser definida como sendo um empreendimento catalisador formado por um grupo de pessoas que possuem ideias inovadoras (Sebrae, 2017), capazes de transformá-las em produtos ou negócios de sucesso no mercado (Ries, 2012b). A startup pode ser compreendida ainda, como sendo uma empresa jovem, embrionária ou em fase de constituição que conta com negócio altamente escalável (Anprotec, 2019a), baixos custos iniciais (Sebrae, 2017), lucrativo, replicáveis (Blank \& Dorf, 2012), com projetos promissores, baseados em pesquisa e investigação (Sebrae, 2017). No entanto, essa categoria de atividade inovadora apresenta como uma das características principais o alto risco envolvido no negócio (Sebrae, 2017), uma vez que as startups são criadas sob cenários de incerteza (Anprotec, 2019a; Ries, 2012a; Ries, 2012b; Sebrae, 2017).

Sendo assim, as startups são projetadas com expectativas de crescimento acentuado (Sebrae, 2017), pois utilizam da tecnologia e inovação como ferramenta estratégica para potencializar o crescimento e replicar seu negócio (Stoilov, 2015). Segundo o levantamento de dados elaborado pela Associação Brasileira de Startups 
(Abstartups, 2019), o Brasil atingiu 12.775 startups em 2019, distribuídas por todo o território nacional, representando $207 \%$ de crescimento, se considerada a base de 2.519 empresas de 2012 (Abstartups, 2019). Embora com apenas 3\% da população brasileira, o Estado de Santa Catarina se destaca com $20 \%$ do total das startups do país (Anprotec, 2019b)

Diante do contexto dos empreendimentos, há um conjunto de técnicas e ferramentas disponíveis para administrar os negócios, bem como melhores práticas para o desenvolvimento de produtos. Entretanto, quando o assunto faz menção às startups e como administrá-las, ainda existem incertezas no modelo de gestão (Ries, 2012b). A utilização dos sistemas de controle gerenciais são diferenciais competitivos no processo decisório dos negócios (Anthony \& Govindarajan, 2008).

Centobelli, Cerchioni e Esposito (2017) indicam algumas lacunas relacionadas à administração das startups: (i) em relação ao nível de alinhamento entre as estratégias e as tecnologias utilizadas; e (ii) o impacto da gestão do conhecimento no desempenho das startups: econômico, financeiro, de mercado, técnico, tecnológico, organizacional e recursos humanos. Carraro, Meneses e Brito (2019) evidenciam que o sucesso das startups depende da combinação entre diferentes práticas de controles gerenciais e das estratégias do negócio, nesse sentido o uso de controles gerenciais são diferenciais para o planejamento das startups, especialmente para minimizar as incertezas do ecossistema.

Nesse contexto, a problemática norteadora da pesquisa visa responder: Quais instrumentos de controles gerenciais são utilizados por startups incubadas? Com o objetivo de identificar a utilização de instrumentos de controles gerenciais em startups incubadas.

Justifica-se a relevância da pesquisa, ponderando que as estratégias organizacionais são baseadas no desenvolvimento de atividades, informações e ferramentas que as startups desenvolvem com base no ambiente externo e interno. A amostra da pesquisa considera 13 startups vinculadas a uma Incubadora de base Tecnológica. Torres e Souza (2016) destacam a carência de trabalhos voltados à 
análise da utilização de algum tipo de ferramenta na gestão do modelo de negócios das startups para auxiliar o processo de tomada de decisões.

Nessa perspectiva, a partir da análise da intensidade do uso de instrumentos de controle, este estudo poderá gerar reflexões a melhorar as dimensões do uso dos sistemas de controles gerenciais adotados pelas startups, assim como no desenvolvimento de atividades e informações voltados ao gerenciamento dos recursos e serviços que darão subsídio à tomada de decisões, podendo ainda auxiliar no suporte de outras demandas latentes voltadas para o empreendedorismo e inovação.

\section{REVISÃO DA LITERATURA}

Nesta seção aborda-se o contexto dos estágios presentes nas fases de incubação das startups a importância dos sistemas de controles gerenciais.

\subsection{Processos de incubação: ciclo de vida das startups}

As incubadoras de empresas apresentam diferentes estágios de apoio ao desenvolvimento de empreendimentos, que abrangem desde o abrigo dos primeiros projetos até aqueles completamente consolidados (Raupp \& Beuren, 2009). Para os autores Raupp e Beuren (2009), o ciclo de vida das empresas incubadas inicia-se com a sua seleção para ingressar na incubadora e termina com a sua graduação, ou seja, processo de incubação é composto por cinco etapas: (i) seleção; (ii) implantação; (iii) desenvolvimento; (iv) crescimento; e (v) liberação.

Por outro lado, Aranha (2008) expõe que as empresas incubadas transitam pelos seguintes estágios: (i) pré-incubação; (ii) seleção; (iii) incubação; (iv) graduação; e (iv) pós-incubação. A Tabela 1, apresenta as características distintas das fases de incubação: 
Tabela 1

Fases de incubação

\begin{tabular}{|c|c|c|}
\hline Fase & Característica & Autores \\
\hline $\begin{array}{l}\text { Pré- } \\
\text { incubação }\end{array}$ & $\begin{array}{l}\text { Acontece por tempo determinado. Empreendedor poderá estar } \\
\text { finalizando sua ideia utilizando todo o suporte disponibilizado pela } \\
\text { incubadora. Ocorre a idealização e a concepção do } \\
\text { empreendimento. }\end{array}$ & $\begin{array}{l}\text { Aranha (2008); } \\
\text { Itep (2020); } \\
\text { Sebrae (2019) }\end{array}$ \\
\hline Seleção & $\begin{array}{l}\text { Busca identificar as propostas empreendedoras que apresentam } \\
\text { maior probabilidade de sucesso; geralmente ocorre por meio de } \\
\text { consórcio. Leva em consideração as características } \\
\text { administrativas, de mercado, de produto e financeiras da } \\
\text { empresa. }\end{array}$ & $\begin{array}{l}\text { Aranha (2008); } \\
\text { Bizzotto (2003); } \\
\text { Hackett e Dilts } \\
\text { (2004); Raupp e } \\
\text { Beuren (2009); }\end{array}$ \\
\hline Incubação & $\begin{array}{l}\text { Nesta fase as empresas apresentam-se constituídas ou em fase } \\
\text { de constituição, dispondo de um plano de negócios estruturado, } \\
\text { domínio de tecnologia, processo de produção e capital mínimo } \\
\text { assegurado para início de suas operações e faturamento. É de } \\
\text { suma importância, neste momento, a revisão constante do plano } \\
\text { de negócios do empreendimento incubado abrangendo assim os } \\
\text { aspectos relativos à forma de organização, tecnologia } \\
\text { empregada, realização de contatos comerciais, forma de } \\
\text { divulgação das atividades, produtos e serviços, bem como a } \\
\text { atuação com os clientes. }\end{array}$ & $\begin{array}{l}\text { Aranha }(2008) \\
\text { Itep }(2020) \\
\text { Sebrae }(2019)\end{array}$ \\
\hline Graduação & $\begin{array}{l}\text { Corresponde ao momento do desligamento da empresa } \\
\text { residente, ao espaço físico da incubadora. A empresa está apta } \\
\text { para ingressar no mercado. Deixa de receber os serviços } \\
\text { pertinentes. Na categoria de associada, a empresa graduada se } \\
\text { desejar poderá continuar mantendo contato com a incubadora e } \\
\text { utilizar dos seus serviços. }\end{array}$ & $\begin{array}{l}\text { Aranha (2008); } \\
\text { Azevedo e } \\
\text { Teixeira (2016) }\end{array}$ \\
\hline $\begin{array}{l}\text { Pós- } \\
\text { incubação }\end{array}$ & $\begin{array}{l}\text { A fase de pós-incubação consiste no apoio da incubadora à fase } \\
\text { de crescimento e consolidação do negócio frente ao mercado de } \\
\text { atuação. Após o período de incubação, a empresa incubada } \\
\text { continua associada. As empresas incubadas continuam } \\
\text { recebendo suporte técnico e empresarial das incubadoras. }\end{array}$ & $\begin{array}{l}\text { Aranha }(2008) \\
\text { Itep }(2020) \\
\text { Sebrae }(2019) \\
\text { Storopoli; Binder } \\
\text { e } \quad \text { Maccari } \\
(2013) \quad\end{array}$ \\
\hline
\end{tabular}

Nota. Fonte: Elaborado pelas autoras.

Com base no modelo de ciclo de vida organizacional de Lester, Parnell e Carraher (2003), os autores Silva, Krakauer e Coda (2020) identificaram que as startups brasileiras se apresentam nos seguintes estágios: (i) estágio de nascimento, cujo empreendimento realiza análise do mercado e parcerias estratégicas; (ii) estágio de crescimento, nesta etapa a elaboração de estratégias com foco na inovação é essencial, tanto para incrementação de seus produtos/serviços como para o 
desenvolvimento, e (iii) estágio de declínio, ressalta-se a importância do suporte teórico e prático transmitidos pelas incubadoras, aceleradoras e parques tecnológicos ainda na fase de idealização, para que o empreendimento consiga ter maturação, crescer e se renovar, reduzindo assim, o índice de mortalidade das startups brasileiras.

A literatura apresenta distintas nomenclaturas para o ciclo de incubação, Dornelas (2002) afirma que o processo engloba as seguintes fases: (i) Implantação; (ii) Crescimento; (iii) Consolidação e (iv) Desincubação. E embora as distinções de nomenclatura, é evidente que as fases incluem a formalização da ideia até a concretização do negócio, o último estágio do ciclo conhecido como desincubação, liberação ou graduação, a empresa está se preparando para dar continuidade as suas atividades e ingressar efetivamente no mercado (Bizzotto, 2003; Cardoso, Kruglianskas, Lupoli Junior, \& Igari, 2008; Dornelas, 2002; Ribeiro \& Andrade, 2008). Cabe destacar que independentemente da fase, não existe restrição do ramo de atuação das startups, além disso independem do tamanho e setor econômico (Anprotec, 2019a). Embora o apelo para a inovação (Kohler, 2016; Ries, 2012a) incentive as incubadoras de base tecnológica.

\subsection{Sistemas de controle gerenciais voltados para as startups}

Os controles gerenciais podem ser utilizados como ferramenta estratégica das organizações (Govindarajan, 1988; Mintzberg, Lampel, Quinn, \& Ghoshal, 2006), uma vez que fornecem informações de suporte para a tomada de decisões (Henri, 2006). O Sistema de Controle Gerencial (SCG) baseia-se em procedimentos e sistemas formalizados que utilizam a informação para manter ou alterar os padrões de uma atividade organizacional (Henri, 2006). O SCG orienta o comportamento dos gestores na direção de estratégias (Anthony \& Govindarajan, 2008). Avaliar o desempenho empresarial torna-se relevante para o controle e a definição de estratégias (Kruger \& Petri, 2014).

Nesse sentido, o SGC pode ser compreendido como sendo um mecanismo facilitador para a elaboração de estratégias de gestão e um dos principais artefatos do 
processo de controle e planejamento (Klein, Beuren, \& Dal Vesco, 2019). Ao analisar a literatura pode-se dizer que não existe apenas uma nomenclatura para designar os instrumentos de controle gerencial (Santos, Beuren, \& Conte, 2017). Frezatti, Rocha, Nascimento e Junqueira (2009) fazem uso da nomenclatura "artefato" como forma de classificar as práticas, instrumentos, sistemas, ferramentas e outras técnicas em geral, que auxiliam a contabilidade gerencial e contribuem para a prática organizacional, por meio de conceitos (representações abstratas), modelos, ferramentas ou sistemas. A utilização de SCG garante o alinhamento entre os objetivos e as estratégias organizacionais, apoiando o processo de tomada de decisões (Kruger, Simionato, Zanella, \& Petri, 2018; Pederssetti \& Kruger, 2020).

O uso de instrumentos gerenciais conhecidos como artefatos modernos da contabilidade gerencial, como: custeio meta (target costing), custeio baseado em atividades ( $\mathrm{ABC})$, custeio kaisen, just in time, valor econômico agregado (EVA), gestão baseada em valor (VBM), planejamento estratégico, balanced scorecard, benchmarking, teoria das restrições e gestão baseada em atividades, entre outros, são instrumentos de apoio ao processo de gestão (Campos, Marques, \& Correia Neto, 2019). Dentre os artefatos modernos presentes no ambiente das startups destaca-se o planejamento estratégico (Rocha, Olave, \& Ordonez, 2019). Carraro et al. (2019) ressaltam que cada empresa pode utilizar mecanismos de controle tanto formais como informais, dependendo de suas necessidades.

Ao analisar a intensidade do uso dos instrumentos de controle gerencial em 29 startups incubadas, Santos, Beuren e Conte (2017) indicam a heterogeneidade entre os instrumentos utilizados com destaque para o planejamento estratégico e financeiro, o que sugere que inicialmente as empresas incubadas estão mais concentradas com a concepção de suas ideias, e posteriormente com a operacionalização e formalização dos instrumentos de controle. Embora as startups apresentem-se como empreendimentos inovadores e os instrumentos de planejamento estratégico têm se destacado na literatura, Rocha, Olave e Ordonez (2020) argumentam que as startups não têm adotado de maneira significativa estratégia de inovação aberta, no entanto, 
sinalizam que atores institucionais como universidades são grandes catalizadores de inovação.

Por outro lado, Beuren, Santos e Theiss (2018) indicam que ocorre a utilização de controles gerenciais formais no estágio inicial de empresas incubadas. Na amostra de 45 startups instaladas em Parques Tecnológicos de Centros Universitários em Portugal, a fim de identificar o uso de instrumentos e práticas de controle gerencial em nove categorias de análise dentro de uma organização, sendo elas: Clientes, Estratégia, Sistemas de Informação, Qualidade, Desempenho, Colaboradores, Riscos, Orçamento e Custos. Os achados revelam que as empresas pesquisadas têm adotado o planejamento de metas e ações de curto prazo, com foco tático, e controles informais, enraizados em crenças e valores, em detrimento dos controles formais, exercidos a partir do estabelecimento de medidas explícitas e verificáveis. Contudo, os autores concluíram que o uso de controles gerenciais formais no estágio é importante para o crescimento de empresas iniciantes, no caso de empresas incubadas.

Davila e Foster (2007) investigaram a evolução da adoção do SCG em 78 empresas startups. Os achados sugerem que os sistemas de planejamento financeiro (que incluem orçamentos operacionais, projeções de fluxo de caixa e projeções de vendas) são consistentemente as modalidades mais utilizados em todas as oito categorias de instrumentos de gestão analisadas. Observaram que a adoção de SCG em startups é potencialmente uma prática importante em seu crescimento, bem como os CEOs que não costumam fazer uso de sistemas de controle de gestão apresentam maior probabilidade de a serem substituídos.

Já o estudo de Davila, Foster e Jia (2015) analisou o impacto da adoção dos SCG na avaliação da empresa, visando averiguar o valor percebido pelos investidores. O estudo teve como amostra 66 empresas startups fundadas entre 1990 e 2008, localizadas em diversos países como Argentina, Austrália, China, Espanha, Estados Unidos, Irlanda. Os resultados sinalizam que os SCG adotados por empresas startups são valorizados pelos financiadores externos, e que a valorização dos SCG é mais 
propensa em empresas estabelecidas em ambientes competitivos e com potencial de crescimento.

O estudo de Dyczkowski e Dyczkowska (2018) evidenciou se o uso do SCG em startups tem natureza proativa ou reativa. A amostra foi composta por 45 empresas startups da Polônia, a partir das perspectivas dos gerentes e funcionários regulares. Os achados demonstraram que mais da metade da amostra monitorou a eficácia do trabalho, produção ou serviços e gerenciamento dos custos ou da qualidade. Os achados indicam que as startups valorizaram o uso de índices não financeiros para a gestão de desempenho, bem como não há distinção do uso de SCG pela idade, indicando que as startups estudadas possuem natureza proativa, em vez de atitude reativa em relação aos controles gerenciais.

De forma geral, observa-se que o uso de SCG nas startups pode ser considerado um grande vetor de informações e instrumentos norteadores de tomada de decisões, auxiliando os gestores na condução de práticas e estratégias empresariais. Nota-se, ainda, que a adoção dos SCG pode estar associada com as expectativas de ascensão das startups, especialmente aquelas que operam em mercados ou ramos mais dinâmicos e incertos. Possivelmente, as startups durante as primeiras fases de incubação passam por mudanças, adaptações frente da inovação e limitação de recursos.

\section{PROCEDIMENTOS METODOLÓGICOS}

A presente pesquisa se caracteriza quanto aos objetivos como descritiva, realizada por meio de levantamento, a partir de questionário de pesquisa, com análise de cunho quantitativo. A população da pesquisa compreendeu startups entre estágios de idealização a pós-graduação, vinculadas a uma incubadora certificada pelo Centro de Referência para Apoio a Novos Empreendimentos (Cerne), localizada na região oeste do estado de Santa Catarina, Brasil. 
A incubadora foi selecionada de forma intencional (Creswell, 2010), pelo fato do Município de Chapecó ter sido considerado a segunda cidade brasileira com maior densidade de startups (Matos, 2017). A incubadora Tecnológica da Unochapecó INCTECh foi implantada em 2003, com o objetivo de incentivar a criação de novos negócios de base tecnológica visando fomentar e desenvolver a economia local. A entidade está localizada junto à Universidade Comunitária da Região de ChapecóUnochapecó e dispõe às empresas incubadas de uma área de aproximadamente $140 \mathrm{~m}^{2}$, as quais têm acesso também aos laboratórios, salas, auditórios e a biblioteca da universidade. Atualmente possui 26 empresas em processo de incubação e conta com 13 empresas graduadas.

Quanto ao instrumento de coleta de dados procedeu-se por meio de questionário, os quais foram enviados aos gestores das startups via Google Docs, entre os meses de março e abril de 2020. A amostra do estudo contemplou 13 startups. Para identificação da intensidade de uso dos instrumentos de Sistema Controle Gerencial foi utilizado o modelo do construto da pesquisa adaptado de Santos et al. (2017) e Aranha (2008), considerando 3 variáveis, 7 subvariáveis, e contemplando 44 itens de avaliação. A coleta de dados abordou ainda, questões sobre o perfil dos participantes e das startups, assim como informações a respeito do estágio de incubação das startups: (i) pré-incubação; (ii) seleção; (iii) incubação; (iv) graduação; (iv) pós-incubação, fundamentada na classificação adotada na pesquisa de Aranha (2008).

Os resultados são apresentados na forma de Tabelas, evidenciando as respostas obtidas quanto à intensidade do uso dos instrumentos de controle gerencial pelas startups da amostra. Utilizou-se de estatística descritiva para apresentar os resultados (mínimo, máximo, média e desvio padrão), acerca das respostas obtidas para cada um dos 44 itens de avaliação. 


\section{ANÁLISE E INTERPRETAÇÃO DOS RESULTADOS}

Primeiramente inicia-se a análise apresentando a Tabela 2, a qual aborda informações sobre o perfil dos gestores respondentes da pesquisa, destacando o gênero, formação, a faixa etária, função, tempo na função e tempo de atuação nas empresas incubadas.

Percebe-se na Tabela 2 a predominância de gestores do gênero masculino atuando nas startups, com faixa etária de 31 a 40 anos de idade. Apenas um dos participantes informou possuir acima de 50 anos. Ao analisar o nível de formação acadêmica nota-se distribuição homogênea pela formação em cursos de especialização/ MBA e mestrado, demonstrando a evidente busca por conhecimento acadêmico por parte dos respondentes para auxiliar no gerenciamento de seus empreendimentos.

Dentre as funções desenvolvidas pelos participantes destacam-se Diretor/administrador, Chief Executive Officer (CEO)/ Chief Technology Office (CTO) e fundador, em que representam $92 \%$ das empresas pesquisadas. No que concerne ao tempo na função e o tempo de atuação na empresa apresentam-se distribuídos entre o período de quatro meses e seis anos de forma equilibrada. 
Tabela 2

Características do perfil dos respondentes

\begin{tabular}{|c|c|c|c|c|c|}
\hline Gênero & Quant. & $\%$ & Formação & Quant. & $\%$ \\
\hline Masculino & 12 & 92 & Graduação & 3 & 23 \\
\hline \multirow[t]{2}{*}{ Feminino } & 1 & 8 & Especialização/MBA & 5 & 38 \\
\hline & & & Mestrado & 5 & 38 \\
\hline Faixa etária & & & Função & & \\
\hline Até 30 & 3 & 23 & Diretor/Administrador & 5 & 38 \\
\hline 31 a 40 anos & 7 & 54 & CEO/CTO & 4 & 31 \\
\hline 41 a 50 anos & 2 & 15 & Fundador & 3 & 23 \\
\hline Acima de 50 anos & 1 & 8 & Coordenador comercial & 1 & 8 \\
\hline Tempo na função & & & Tempo na empresa & & \\
\hline Até 1 ano & 5 & 38 & Até 1 ano & 4 & 31 \\
\hline 01 a 02 anos & 2 & 15 & 01 a 02 anos & 2 & 15 \\
\hline 03 a 04 anos & 2 & 15 & 03 a 04 anos & 3 & 23 \\
\hline 05 a 06 anos & 4 & 31 & 05 a 06 anos & 4 & 31 \\
\hline
\end{tabular}

Nota. Fonte: Dados da pesquisa.

Para analisar e investigar as características das startups, a Tabela 2 apresenta a distribuição das empresas conforme seu estágio e tempo de incubação, tempo de existência do projeto, setor e ramo de atuação do negócio, número de colaboradores e faturamento entre os anos de 2017 e 2019, bem como seu status da constituição formal.

Ao avaliar o processo de incubação apresentados por meio da Tabela 3, constata-se que $62 \%$ das startups encontram-se no estágio de incubação e 15\% Préincubação. $\mathrm{Na}$ fase de incubação as startups encontram-se constituídas ou em fase de constituição, dispondo de um plano de negócios estruturado, domínio de tecnologia, processo de produção e capital mínimo assegurado para início de suas operações (Sebrae, 2019). Nota-se que a maioria das empresas estão incubadas até 2 anos (84\%) e $38 \%$ menos de um ano.

A Tabela 3 demonstra que com o tempo o negócio vai se organizando, estruturando e dispondo de mais recursos financeiros e assim recursos humanos 
consequentemente. Como pode-se perceber em 2017, das 13 empresas pesquisadas, seis informaram não possuir nenhum colaborador e sete mencionaram possuir até 09 colaboradores em sua equipe. No entanto, em 2019, todas as empresas informaram ter de um a nove colaboradores em seu quadro funcional. Desse modo, ressalta-se que as startups são projetadas com expectativas de crescimento acentuado e rápido, corroborando com os indicativos do Sebrae (2017).

Tabela 3

Características das startups

\begin{tabular}{|c|c|c|c|c|c|c|}
\hline Estágio & Quant. & $\%$ & & Existência do projeto & Quant. & $\%$ \\
\hline Ideação & 1 & 8 & & até 1 ano & 3 & 23 \\
\hline Pré-incubação & 2 & 15 & & 1 a 2 anos & 4 & 31 \\
\hline Incubada & 8 & 62 & & 3 a 4 anos & 3 & 23 \\
\hline Graduação & 1 & 8 & & 5 a 6 anos & 2 & 15 \\
\hline Pós-graduação & 1 & 8 & & & & \\
\hline $\begin{array}{l}\text { Tempo de } \\
\text { incubação }\end{array}$ & & & & Setor de atuação & & \\
\hline até 1 ano & 5 & 38 & & $\begin{array}{l}\text { Agronegócio } \\
\text { Tecnologia da }\end{array}$ & 3 & 23 \\
\hline 1 ano & 3 & 23 & & Informação & 5 & 38 \\
\hline 2 anos & 3 & 23 & & Outros & 5 & 38 \\
\hline 3 anos & 0 & 0 & & Ramo & & \\
\hline 4 anos & 1 & 8 & & Financeiro & 3 & 23 \\
\hline 5 anos & 0 & 0 & & Tecnologia & 3 & 23 \\
\hline 6 anos & 1 & 8 & & Agronegócio & 2 & 15 \\
\hline № Colaboradores & 2017 & 2018 & 2019 & Design de produto & 1 & 8 \\
\hline Nenhum & 6 & 3 & 0 & $\begin{array}{c}\text { Eletrônica } \\
\text { Entretenimento com }\end{array}$ & 1 & 8 \\
\hline 01 a 09 & 7 & 10 & 13 & educação & 1 & 8 \\
\hline Acima de 10 & 0 & 0 & 0 & $\begin{array}{c}\text { Mobilidade Urbana } \\
\text { Telemetria de } \\
\text { Veículos }\end{array}$ & 1 & 8 \\
\hline Faturamento & & & & Frigorificados & 1 & 8 \\
\hline Não houve & 7 & 6 & 2 & Possui CNPJ & & \\
\hline Até $\mathrm{R} \$ 50 \mathrm{mil}$ & 6 & 7 & 7 & Sim & 12 & 92 \\
\hline Acima $\mathrm{R} \$ 50 \mathrm{mil}$ & 0 & 0 & 4 & Não & 1 & 8 \\
\hline
\end{tabular}

Nota. Fonte: Dados da pesquisa. 
Adicionalmente, nota-se a evolução significativa também no setor financeiro, visto que, em 2017, sete (54\%) das startups pesquisadas declararam não gerar faturamento e seis empresas (46\%) que seu faturamento foi de até 50 mil reais neste mesmo ano. E, em 2019, apenas duas das empresas não apresentaram faturamento, sete até 50 mil e quatro empresas dispuseram de faturamento acima de 50 mil reais. Os achados corroboram os estudos de Santos et al. (2017) e Rizzi, Wescinski, Poli, \& Jacoski (2017), cujas empresas em estágio inicial certamente não apresentam faturamento e tão pouco contratam funcionários. Nesta etapa, normalmente buscam focar seus esforços no desenvolvimento de produtos e do seu projeto (Beuren, Conte, \& Theiss, 2018). Entretanto, esses empreendimentos também estão preocupados com o crescimento do faturamento, e, consequentemente, visam o equilíbrio de capital de giro para pagar seus colaboradores internos e externos (Silva et al., 2020).

Tal fato pode estar associado ainda, considerando que a maioria das empresas vinculadas à incubadora são do setor de Tecnologia da informação, e que esse ramo consegue desenvolver seus produtos e serviços na fase inicial de incubação, geralmente atendendo demandas mercadológicas (Rizzi et al., 2017).

Percebe-se que o setor de atuação "Tecnologia da Informação" teve destaque dentre as empresas estudadas, tal resultado é condizente já que utilizam da tecnologia e inovação como ferramenta estratégica para potencializar o crescimento do seu negócio (Rizzi et al., 2017; Stoilov, 2015). Bem como pela incubadora ter esse enfoque tecnológico. Não obstante, as startups usufruem da tecnologia para se sobressair no mercado (Kohler, 2016; Ries, 2012a), pode-se notar que esses negócios não atuam somente ao ramo digital (Anprotec, 2019a), abrangem também outras áreas e soluções (Ries, 2012b), tais como: financeiro, agronegócio, design de produto, eletrônica, entretenimento com educação, mobilidade urbana e telemetria de veículos frigorificados, conforme os ramos de negócios apresentados na Tabela 4. 
Tabela 4

Uso dos instrumentos de planejamento

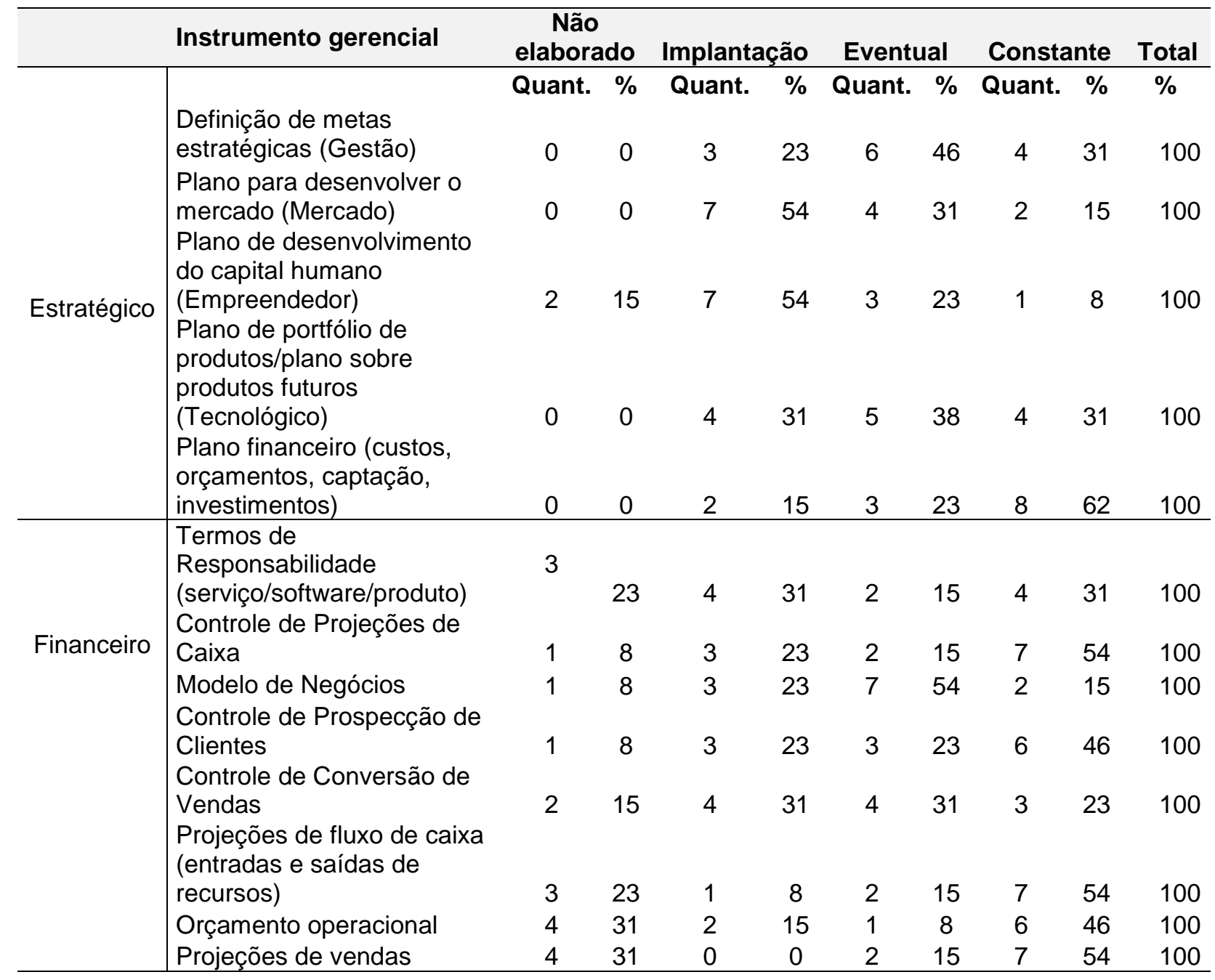

Nota. Fonte: Dados da pesquisa.

Após identificar as características dos respondentes e das empresas iniciantes, apresenta-se a Tabela 4 os resultados da pesquisa no que faz menção à intensidade de uso dos instrumentos de controle gerencial de planejamento, para isso analisou-se se o tipo de instrumento ainda não foi elaborado, se está em fase de implantação ou se é utilizado eventualmente ou constantemente pelos gestores. 
Os resultados demonstrados na Tabela 4 indicam que a maioria dos instrumentos de planejamento estratégico apresentam-se distribuídos na fase de implantação ou sendo utilizados de forma eventual pelos gestores, ou seja, estão sendo utilizados de forma moderada. Tal situação pode-se ser justificada, uma vez que $67 \%$ das empresas estudadas encontram-se em estágio de pré-incubação ou incubadas. Todavia, com exceção do instrumento Plano de desenvolvimento do capital humano (Empreendedor) em que duas startups sinalizaram não adotar essa ferramenta de planejamento, as demais empresas sinalizaram fazer uso de todos os tipos de instrumentos de planejamento estratégico listados, de forma esporádica ou de maneira constante.

Em relação ao uso do instrumento de planejamento financeiro percebe-se que há moderada distribuição entre as respostas, entretanto, pode-se destacar que os instrumentos Controle de Projeções de Caixa, Controle de Prospecção de Clientes, Projeções de fluxo de caixa (entradas e saídas de recursos), Orçamento operacional e Projeções de vendas são utilizados com maior frequência pelas startups. Identificou-se que até quatro startups da amostra sinalizaram não elaborar nenhum dos tipos de planejamento financeiros investigados, isso indica que possivelmente essas empresas estão em estágio de incubação, as quais inclusive não apresentam faturamento nesse momento.

A fim de analisar o uso dos instrumentos de avaliação financeira e de recursos humanos apresenta-se na sequência a Tabela 5.

Observa-se na Tabela 5, a baixa adesão pelo uso dos instrumentos de avalição financeira, mais uma vez reitera-se a ideia de que empresas em fases iniciais do ciclo de vida são mais propensas a não apresentarem faturamento e, consequentemente, não fazem uso de instrumentos gerenciais financeiros. Percebe-se que as respostas se concentram entre as etapas "não utilizado" e "utilizado constantemente", essa última situação pode estar atrelada às empresas incubadas a mais tempo, graduadas ou pósgraduadas. Da mesma maneira, em relação ao uso de instrumentos de avaliação de 
recursos humanos, entre 5 e 9 empresas informaram não utilizarem essas ferramentas de controle.

Tabela 5

Uso dos instrumentos de avaliação

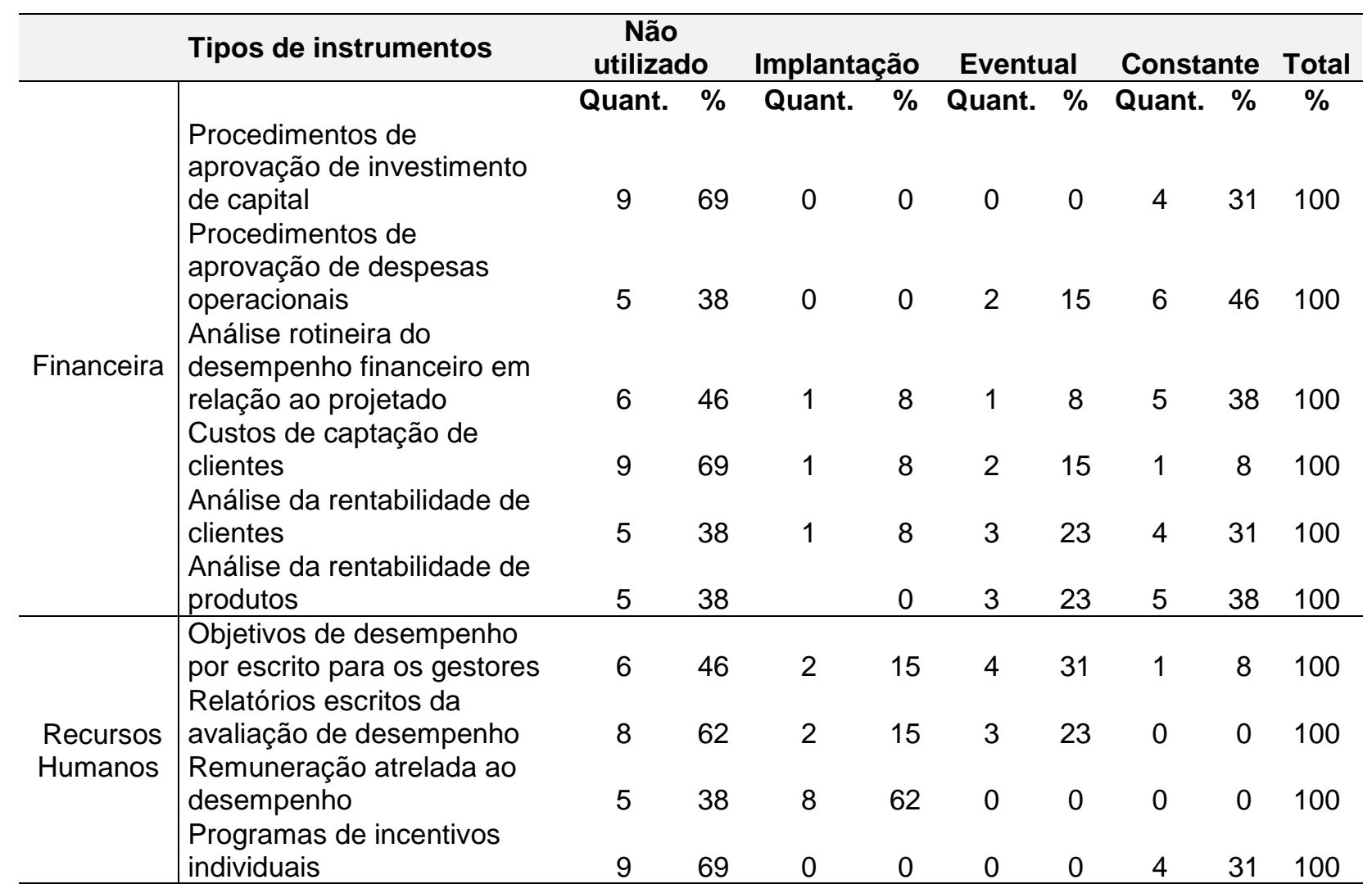

Nota. Fonte: Dados da pesquisa.

Destaca-se ainda, que os instrumentos "objetivos de desempenho por escrito para os gestores" e "relatórios escritos da avaliação de desempenho" foram mencionados estar em fase de implantação ou utilizados eventualmente.

Conforme a Tabela 5, a baixa aderência por instrumentos de avaliação de recursos humanos possivelmente está associada ao número inexpressivo de colaboradores, considerando que, em 2017 , 46\% das startups não possuíam nenhum colaborador, em 2018, das 13 startups (23\%) continuavam sem contratações e apenas, 
em 2019, todas as empresas tinham contratado pelo menos um colaborador, mas nenhuma ultrapassou 10 contratações. Os achados podem estar atribuídos ainda, a constituição recente dessas startups, aos primeiros estágios do processo de incubação e à adoção de outras estratégias e objetivos prioritários (Santos et al., 2017).

$\mathrm{Na}$ Tabela 6, apresentam-se os tipos de instrumentos de gerenciais de gestão de produtos, gestão de vendas e gestão de parcerias. Verifica-se na Tabela 6, que dos instrumentos de gestão de produtos listados, o item "Gerência de marcos/etapas do projeto" com 31\%, "Relatórios comparando o progresso real em relação ao planejado" e 'Processo de seleção de projetos' ambos com $46 \%$ foram mencionados pelos gestores como instrumentos que ainda não foram institucionalizados pelas empresas. Embora esses números sejam expressivos nota-se que os instrumentos se encontram distribuídos entre as fases de implantação e de uso eventual ou contínuo, tal situação condiz com o tempo do ciclo de vida de maturação dessas empresas, pois empresas nas fases finais do processo de encubação encontram-se mais consolidadas. Nota-se, ainda, que os instrumentos mais utilizados pelos gestores são: Processo de teste do conceito de produto, Mapeamento do portfólio de produtos, Orçamento para desenvolvimento de projetos e Diretrizes de composição da equipe de projeto. 
Tabela 6

Uso dos instrumentos de Gestão

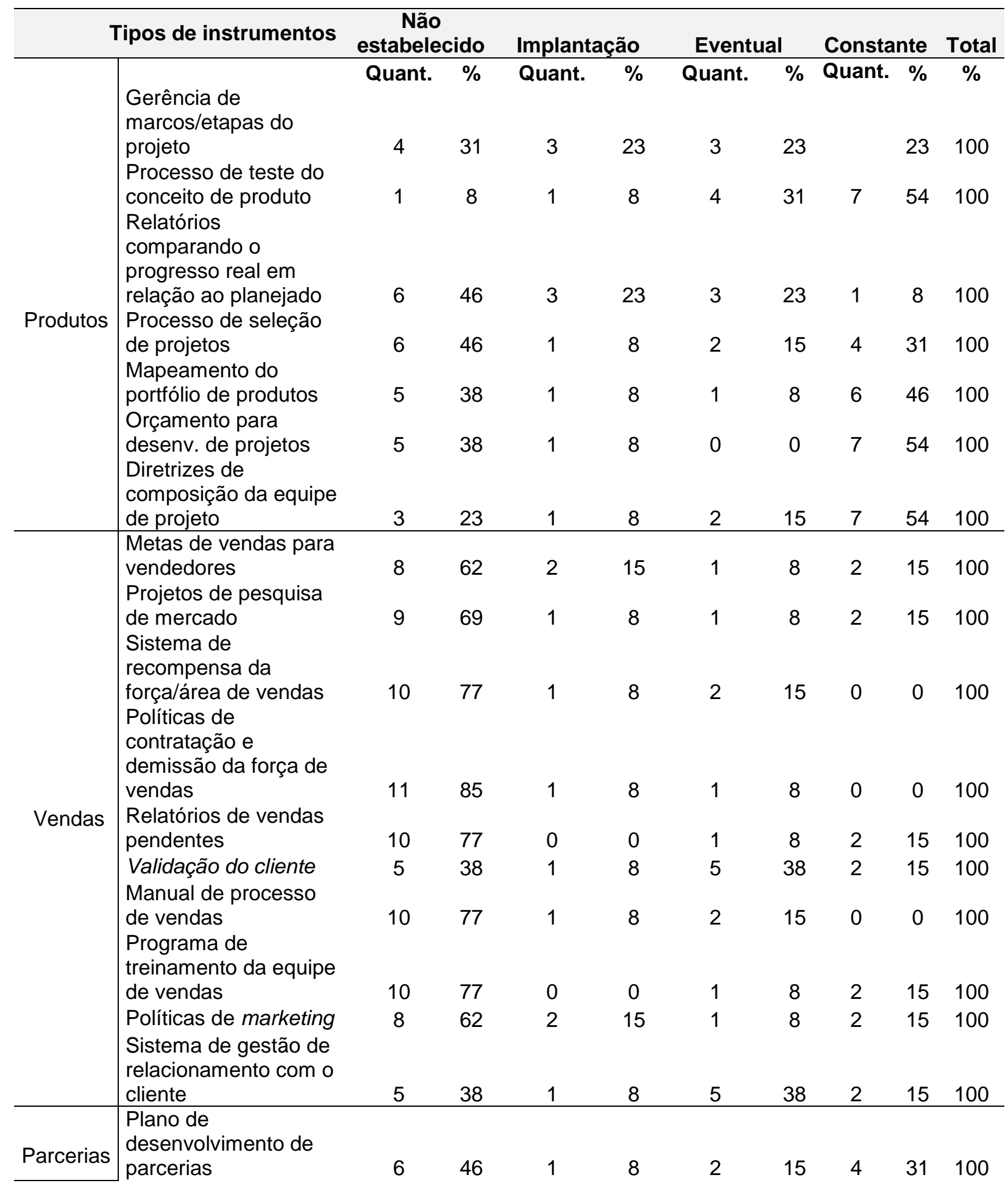




$\begin{array}{llllllllll}\text { Políticas de parcerias } & 5 & 38 & 1 & 8 & 1 & 8 & 6 & 46 & 100 \\ \text { Metas de parcerias } & 7 & 54 & 1 & 8 & 0 & 0 & 6 & 46 & 108 \\ \text { Sistemas de } & & & & & & & & & \\ \text { monitoramento de } & 7 & 54 & 3 & 23 & 2 & 15 & 1 & 8 & 100 \\ \text { parcerias } & 7 & \end{array}$

Nota. Fonte: Dados da pesquisa.

No tocante ao uso do instrumento de gestão de vendas, observa-se que a maioria das startups declaram não utilizarem esses instrumentos de gestão e poucos gestores informaram utilizar eventualmente ou frequentemente. Santos et al. (2017) possivelmente as empresas incubadas desenvolvem algumas práticas de gestão, não obstante não realizam controles e acompanhamento como meio de institucionalização.

Por fim, no que diz respeito à gestão de parcerias verifica-se que entre 5 e 7 startups não estabelecem instrumentos de gestão de parcerias e entre 4 e 6 startups utilizam regularmente os instrumentos "Plano de desenvolvimento de parcerias", "políticas de parcerias" e "metas de parcerias". Cabe assim, considerar o entendimento de que a princípio as startups pesquisadas estão mais concentradas na concepção de suas ideias e focadas no projeto, postergando para o futuro questões voltadas à implementação, operacionalização e controle dos instrumentos, corroborando com os achados de Santos et al. (2017).

$\mathrm{Na}$ Tabela 7 apresentam-se os resultados gerais do estudo, considerando a média de utilização dos controles gerenciais. 
Tabela 7

Resultados gerais do uso de instrumentos de Gestão

\begin{tabular}{|c|c|c|c|c|c|}
\hline Indicadores & Instrumento Gerencial & Mínimo & Máximo & Média & DP \\
\hline \multirow{5}{*}{$\begin{array}{l}\text { Planejamento } \\
\text { Estratégico }\end{array}$} & $\begin{array}{lll}\text { Plano financeiro } & \text { (custos, } & \text { captação, } \\
\text { investimentos) }\end{array}$ & 2 & 4 & 3,4 & 0,77 \\
\hline & $\begin{array}{l}\text { Plano de portfólio de produtos futuros } \\
\text { (Tecnológico) }\end{array}$ & 2 & 4 & 3,2 & 0,72 \\
\hline & Definição de metas estratégicas (Gestão) & 2 & 4 & 3,1 & 0,79 \\
\hline & Plano para desenvolver o mercado (Mercado) & 2 & 4 & 2,7 & 0,75 \\
\hline & Plano de desenvolvimento do capital humano & 1 & 4 & 2,3 & 0,86 \\
\hline \multirow{8}{*}{$\begin{array}{l}\text { Planejamento } \\
\text { Financeiro }\end{array}$} & Controle de Projeções de Caixa & 1 & 4 & 3,0 & 1,04 \\
\hline & Controle de Prospecção de Clientes & 1 & 4 & 2,9 & 1,0 \\
\hline & Modelo de Negócios & 1 & 4 & 2,7 & 0,86 \\
\hline & $\begin{array}{lll}\text { Termos } & \text { de } & \text { Responsabilidade } \\
\text { (serviço/software/produto) } & \end{array}$ & 1 & 4 & 2,6 & 1,23 \\
\hline & Controle de Conversão de Vendas & 1 & 4 & 2,5 & 1,08 \\
\hline & Orçamento operacional & 1 & 4 & 2,5 & 1,37 \\
\hline & $\begin{array}{l}\text { Projeções de fluxo de caixa (entradas/saídas de } \\
\text { recursos) }\end{array}$ & 1 & 4 & 2,1 & 1,44 \\
\hline & Projeções de vendas & 1 & 4 & 2,1 & 1,31 \\
\hline \multicolumn{2}{|c|}{ Variável: Uso dos instrumentos de planejamento } & 1,31 & 4,00 & 2,70 & 1,02 \\
\hline \multirow{6}{*}{$\begin{array}{l}\text { Avaliação } \\
\text { Financeira }\end{array}$} & $\begin{array}{l}\text { Análise rotineira do desempenho financeiro e } \\
\text { projetado }\end{array}$ & 1 & 4 & 2,4 & 1,3 \\
\hline & $\begin{array}{l}\text { Procedimentos de aprovação de despesas } \\
\text { operacionais }\end{array}$ & 1 & 4 & 2,2 & 1,19 \\
\hline & Custos de captação de clientes & 1 & 4 & 1,8 & 1,03 \\
\hline & $\begin{array}{l}\text { Procedimentos de aprovação de investimento de } \\
\text { capital }\end{array}$ & 1 & 4 & 1,7 & 1,05 \\
\hline & Análise da rentabilidade de clientes & 1 & 3 & 1,4 & 0,64 \\
\hline & Análi & 1 & 2 & 1,3 & 0,45 \\
\hline \multirow{4}{*}{$\begin{array}{l}\text { Avaliação de } \\
\text { Recursos } \\
\text { Humanos }\end{array}$} & empenho & 1 & 4 & 3,2 & 0,94 \\
\hline & to de desempenho & 1 & 4 & 2,5 & 1,23 \\
\hline & Programas de incentivos individuais & 1 & 4 & 1,9 & 1,08 \\
\hline & $\begin{array}{l}\text { Objetivos de desempenho por escrito para os } \\
\text { gestores }\end{array}$ & 1 & 3 & 1,4 & 0,77 \\
\hline \multicolumn{2}{|c|}{ Variável: Uso dos instrumentos de avaliação } & 1,00 & 3,60 & 1,96 & 0,97 \\
\hline \multirow{7}{*}{$\begin{array}{l}\text { Gestão de } \\
\text { Produtos }\end{array}$} & Mapeamento do portfólio de produtos & 1 & 4 & 2,8 & 1,27 \\
\hline & Diretrizes de composição da equipe de projeto & 1 & 4 & 2,7 & 1,35 \\
\hline & $\begin{array}{l}\text { Relatórios comparando o progresso real com o } \\
\text { planejado }\end{array}$ & 1 & 4 & 2,5 & 1,44 \\
\hline & Orçamento para desenvolvimento de projetos & 1 & 4 & 2,5 & 1,3 \\
\hline & Processo de teste do conceito de produto & 1 & 4 & 2,3 & 1,29 \\
\hline & Processo de seleção de projetos & 1 & 4 & 2,1 & 1,44 \\
\hline & Gerência de marcos/etapas do projeto & 1 & 4 & 2,0 & 1,21 \\
\hline \multirow{2}{*}{$\begin{array}{l}\text { Gestão de } \\
\text { Vendas }\end{array}$} & Validação do cliente & 1 & 4 & 2,2 & 1,19 \\
\hline & Sistema de gestão de relacionamento com o & 1 & 4 & 2,2 & 1,19 \\
\hline
\end{tabular}




\begin{tabular}{|c|c|c|c|c|c|}
\hline & \multicolumn{5}{|l|}{ cliente } \\
\hline & Metas de vendas para vendedores & 1 & 4 & 1,9 & 1,16 \\
\hline & Projetos de pesquisa de mercado & 1 & 4 & 1,8 & 1,19 \\
\hline & Relatórios de vendas pendentes & 1 & 4 & 1,7 & 1,21 \\
\hline & Programa de treinamento da equipe de vendas & 1 & 4 & 1,7 & 1,21 \\
\hline & Sistema de recompensa da força/área de vendas & 1 & 3 & 1,5 & 0,78 \\
\hline & Manual de processo de vendas & 1 & 3 & 1,5 & 0,78 \\
\hline & $\begin{array}{l}\text { Políticas de contratação e demissão da força de } \\
\text { vendas }\end{array}$ & 1 & 3 & 1,3 & 0,62 \\
\hline & Políticas de marketing & 1 & 4 & 1,19 & 1,16 \\
\hline & Políticas de parcerias & 1 & 4 & 2,4 & 1,37 \\
\hline Gestão de & Metas de parcerias & 1 & 4 & 2,2 & 1,4 \\
\hline Parcerias & Plano de desenvolvimento de parcerias & 1 & 4 & 2,0 & 1,21 \\
\hline & Sistemas de monitoramento de parcerias & 1 & 4 & 1,7 & 1,05 \\
\hline Variável: Us & os instrumentos de Gestão & 1,00 & 3,86 & 2,03 & 1,18 \\
\hline
\end{tabular}

Nota. Fonte: Dados da pesquisa.

Por meio da Tabela 7, apresenta-se os instrumentos mais utilizados, por subvariável, pelos gestores. Assim os achados revelam que a maior adesão com relação aos instrumentos de planejamento foram: Plano financeiro, Plano de portfólio de produtos/plano sobre produtos futuros (Tecnológico), Controle de Projeções de Caixa e Controle de Projeções de Clientes.

No que tange aos instrumentos de avaliação destacaram-se: Análise rotineira do desempenho financeiro em relação ao projetado, Procedimentos de aprovação de despesas operacionais, Remuneração atrelada ao desempenho e Relatórios escritos da avaliação de desempenho. Por fim, apresenta-se os instrumentos com maior predominância referente a gestão: Mapeamento do portfólio de produtos, Diretrizes de composição da equipe de projeto, Validação do cliente, Sistema de gestão de relacionamento com o cliente, Políticas de parcerias e Metas de parcerias.

Levando-se em consideração que as startups são negócios promissores e de dimensões escaláveis, pois exploram atividades inovadoras por meio de produtos e/ou serviços disruptivos como forma de competição no mercado. Nesse sentido, cabe-se uma análise de forma específica do uso desses instrumentos gerenciais frente ao cenário incerto. Como por exemplo, com relação à subvariável o planejamento nota-se 
menor predisposição pelo uso dos instrumentos "Definição de metas estratégicas" e "Plano para desenvolver o mercado" comparados ao item "Planejamento financeiro" com maior média $(3,4)$, assim, percebe-se que nesse momento do processo de incubação, as companhias estão mais focadas em captar recursos para que futuramente possam elaborar estratégias de mercado. Pondera-se ainda que essa condição como uma fragilidade, visto que mesmo nesse ciclo de maturação, a análise do ambiente externo é considerada fundamental para os negócios.

Ao analisar algumas potencialidades, embora as companhias adotem de forma mais intensa os instrumentos "Gestão de mapeamento do portfólio de produtos", "Gestão de Diretrizes de composição da equipe de projeto de produtos", "Gestão de validação do cliente", nota-se na amostra das startups estudadas a fragilidade em planejar as projeções em vendas, bem como acompanhar a análise da rentabilidade de produtos.

Observa-se também que a Gestão de Políticas de marketing e Gestão de sistemas de monitoramento de parcerias apresentaram-se como mecanismos de frágil intensidade, ou seja, indicados com baixo uso pelos gestores. Depreende-se que à medida que essas organizações vão passando da fase de maturação para graduação, e assim se consolidando no mercado as fragilidades observadas, vão sendo trabalhadas e incorporadas nas práticas de gestão de maneira mais expressiva e simultâneas. Adicionalmente, estabelece-se novas metodologias de cooperação de conhecimento entre seus funcionários, clientes e parceiros (Lins Filho, Andrade \& Silva, 2020).

Por fim, observa-se que dentre as variáveis observadas pelo estudo, com a amostra da pesquisa, a que apresentou maior destaque quanto a intensidade da utilização foi a variável planejamento (média 2,70$)$, seguida de gestão $(2,03)$ e por último avaliação $(1,96)$.

Nesse sentido pode-se inferir que as startups nessa fase de iniciação estão mais empenhadas na elaboração de atividades e práticas de gestão, todavia, mostram-se pouco focadas em estabelecer instrumentos de avaliação e controle gerencial ou, 
possivelmente, essa ferramenta encontra-se em fase de institucionalização, alinhandose aos estudos de Santos et al. (2017). Sendo assim ao comparar os achados por subvariável, percebe-se que a intensidade do uso dos instrumentos diverge dos resultados Santos et al. (2017), ou seja, a prioridade pelos instrumentos de planejamento, avaliação e gestão podem ser utilizados de maneira diferente, podendo estar associado à modalidade da incubadora e ao contexto do segmento de atuação dos empreendimentos incubados.

\section{CONSIDERAÇÕES FINAIS}

Este estudo teve como objetivo identificar a intensidade do uso de instrumentos de controle gerencial em empresas startups incubadas. A literatura consultada possibilitou observar incipientes trabalhos teóricos que analisam como os artefatos gerenciais podem auxiliar as empresas startups no controle e informações em diferentes fases de incubação. Os procedimentos utilizados para realização do estudo permitiram obter uma amostra de 13 empresas incubadas, localizadas na região oeste do estado de Santa Catarina, referente ao ano de 2020.

Os resultados evidenciam que a maioria das startups investigadas se concentram nas fases de pré-incubação ou incubação. Em relação ao faturamento, constatou-se expressiva evolução dos recursos no decorrer dos anos de 2017 a 2019. A medida que as empresas vão se consolidando, gradualmente há crescimento no seu faturamento. Os principais achados apontam que os instrumentos de planejamento estratégico se apresentam distribuídos na fase de implantação ou sendo utilizados de forma eventual pelos gestores. Em relação ao uso do instrumento de planejamento financeiro percebeu-se que há moderada distribuição no que tange a intensidade do uso, porém poucas startups sinalizaram não fazer uso desse instrumento. Os resultados indicam também que é inexpressiva a adesão pelo uso dos instrumentos de avaliação financeira e de recursos humanos, possivelmente pela estrutura pequena e com poucos colaboradores. 
Quanto ao instrumento gestão de produtos, vendas e parcerias conclui-se que há heterogeneidade quanto a intensidade do uso, ao constar que das 13 startups estudadas, oito delas indicam não utilizar com efetividade instrumentos de gestão de produtos e 5 informaram usar constantemente, sobre o instrumento gestão de parcerias 9 informaram ainda não implementar essa subvariável ao passo que em média 4 empresas sinalizaram já ter esse mecanismo de controle institucionalizado.

Os resultados demonstram a predominância pela variável planejamento (média 2,70), comparada à gestão $(2,03)$ e à avaliação $(1,96)$. A adoção de controles gerenciais formais, nos primeiros estágios de incubação são relevantes para 0 crescimento das startups para minimizar as incertezas do ecossistema e garantir o crescimento sustentável do negócio. Entretanto, constatou-se que as empresas startups utilizam os instrumentos de instrumento de controle gerencial de forma parcial e circunstancial.

Dentre as limitações do estudo, pode-se considerar o fato do estudo avaliar apenas empresas localizadas na região oeste do estado de Santa Catarina, ficando limitada a amostra. Como proposta para estudos futuros sugere-se que seja realizado um estudo comparativo entre empresas incubadas e pós-graduadas quanto à utilização de instrumentos de controle gerencial, além da ampliação da amostra, a fim de gerar reflexões acerca da necessidade de melhoria do gerenciamento de recursos e serviços que darão subsídio à tomada de decisões dos gestores, em decorrência do tempo de consolidação e da intensidade de práticas gerenciais adotadas pelas startups.

\section{REFERÊNCIAS}

Anthony, R. N., \& Govindarajan, V. (2008). Sistemas de controle gerencial. (12a ed.). Porto Alegre, AMGH.

Aranha, J. A. S. (2008). Incubadoras. In: Parolin, S. R. H., \& Volpato, M. Faces do empreendedorismo inovador. Curitiba: SENAI/SESI/IEL.

Azevedo, I. S. C., \& Teixeira, C. S. (2016). (Orgs). Incubadoras: alinhamento conceitual. Florianópolis: Perse. E-book. Recuperado de: http: //via.ufsc.br. Acesso em: 16 jul. 2020. 
Brasscom, Associação Brasileira das Empresas de Tecnologia da Informação e Comunicação. (2019). Relatório Startups. Recuperado de: http://www.brasilitplus.com/brasilit/upload/download/1416332923startups.pdf. Acesso em: 08 dez.2019.

Abstartups, Associação Brasileira de Startups. (2020). Crescimento das startups: veja o que mudou nos últimos cinco anos! Recuperado de: https://abstartups.com.br/crescimento-das-startups. Acesso em: 24 fev. 2020.

Anprotec, Associação Nacional de Entidades Promotoras de Empreendimentos Inovadores. (2019a). Mecanismos de geração de empreendimentos e ecossistemas de inovação. Recuperado de: http://anprotec.org.br/site/sobre/incubadoras-eparques. Acesso em: 08 nov. 2019.

Anprotec, Associação Nacional de Entidades Promotoras de Empreendimentos Inovadores. (2019b). Ambiente da Inovação Brasileira. Brasília/DF: Locus, ed. 85. Recuperado de: https://informativo.anprotec.org.br/locus87. Acesso em: 16 jul. 2020.

Beuren, I. M., dos Santos, V., \& Theiss, V. (2018). Análise da formalidade dos sistemas de controle gerencial em empresas incubadas. Revista Mineira de Contabilidade, Belo Horizonte, 19(2), 19-30.

Bizzotto, C. E. N. O. (2003). Processo de Incubação. Brasília: InfoDev Incubator Support Center (iDISC).

Blank, S., \& Dorf, B. (2012). The Startup Owner's Manual: The Step-by-Step Guide for Building a Great Company. Califórnia: K\&S Ranch Press.

Campos, L. C., Marques, V., \& Correia Neto, F. (2019). Fatores que influenciam a utilização de artefatos de contabilidade gerencial em empresas cearenses. Revista de Administração da UNIMEP, 17(1), 34-64.

Cardoso, A. C. F., Kruglianskas, I., Lupoli Junior, J. G., \& Igari, A. T. (2008). Incubadoras orientadas para o desenvolvimento sustentável: é possível? O caso do Centro de Incubação de Empresas de Tecnologia (CIETEC). Revista de Gestão Social e Ambiental, 2(2), 69-87.

Carraro, W. B. W. H., Meneses, R., \& Brito, C. (2019). Combinação de categorias de práticas de controle de gestão para o alto desempenho de start-ups. Revista brasileira de Gestão de Negócios, São Paulo, 21(4), 861-878.

Centobelli, P., Cerchione, R., \& Esposito, E. (2017). Knowledge Management in Startups: Systematic Literature Review and Future Research Agenda. Sustainability, 9(3), 361-380, 2017. 
Creswell, J. W. W. (2010). Projeto de pesquisa: métodos qualitativo, quantitativo e misto. (2a ed.). Porto Alegre: Bookman.

Davila, A., \& Foster, G. (2007). Management control systems in early-stage startup companies. The Accounting Review, 82(4), 907-937.

Davila, A., Foster, G., \& Jia, N. (2015). The valuation of management control systems in start-up companies: International field-based evidence. European Accounting Review, 24(2) 207-239.

Dornelas, J. C. A. (2002). Planejando incubadoras de empresas: como desenvolver um plano de negócios para as incubadoras. Rio de Janeiro: Campus.

Dyczkowski, T., \& Dyczkowska, J. (2018). Management control for start-up companies fragmented efforts or a unified framework? Wroclaw, 515. DOI: $10.15611 / p n .2018 .515 .06$

Itep, Instituto de Tecnologia de Pernambuco. (2020). Processo de incubação. Recuperado de: http://www.itep.br/processo-de-incubacao. Acesso em: 13 ago. 2020.

Frezatti, F., Rocha, W., do Nascimento, A., \& Junqueira, E. (2009). Controle gerencial: uma abordagem da contabilidade gerencial no contexto econômico, comportamental e sociológico. São Paulo: Atlas.

Govindarajan, V. A. (1988) Contingency approach to strategy implementation at the businessunit level: integrating administrative mechanisms with strategy. Academy of Management Journal, 31(4), 828-853.

Hackett, S. M., \& Dilts, D. M. (2004). A systematic review of business incubation research. Journal of Technology Transfer, Indianapolis, 29(1), 55-82.

Henri, J. F. (2006). Management control systems and strategy: a resource-based perspective. Accounting, Organizations and Society, 31(6), 529-558.

Klein, L., Beuren, I. M., \& Dal Vesco, D. (2019). Effects of the Management control system in unethical behaviors. RAUSP Management Journal, 54(1), 54-76.

Kruger, S. D., \& Petri, S. M. (2014). Novas evidências da relação entre medidas tradicionais de desempenho e aquelas baseadas na geração de valor a partir do custo de capital. Revista Universo Contábil, 10(2), 125-143.

Kruger, S. D., Simionato, A., Zanella, C., \& Petri, S. M. (2018). Balanced scorecard: a proposal for strategic management of a rural cooperative credit. Revista de Administração da UFSM, 11(1), 1-18. 
Kohler, T. (2016). Corporate accelerators: Building bridges between corporations and startups. Business Horizons, 59, 347-357.

Lins Filho, M. L., Andrade, A. P. V., \& Silva, G. G. (2020). Capacidade de Inovar em Startups: Uma Abordagem sob a Ótica da Orientação para Aprendizagem. NAVUS Revista de Gestão e Tecnologia, 10(1),1-21.

Matos, F. (2017). Qual a região campeã em densidade de startups no Brasil? Você vai se surpreender. Estadão, São Paulo. Recuperado de: http://link.estadao.com.br/blogs/felipe-matos/qual-a-regiao-campea-em-densidadede-startups-no-brasil-voce-vai-se-surpreender. Acesso em: 15 dez. 2019.

Mintzberg, H., Lampel, J., Quinn, J. B., \& Ghoshal, S. (2006). O processo da estratégia. (4a ed.). Porto Alegre: Bookman.

Pederssetti, W. C., \& Kruger, S. D. (2020). Análise dos Sistemas de Controles Gerenciais e a Interface com 0 Ciclo de Vida de uma Indústria de Alimentos. ABCustos, 15(3).

Raupp, F., \& Beuren, I. M. (2009). Programas oferecidos pelas incubadoras brasileiras às empresas incubadas. Revista de Administração e Inovação, 6(1), 83-107.

Ribeiro, A. C. S., \& Andrade, E. P. (2008). Modelo de gestão para incubadora de empresas sob a perspectiva de metodologias de gestão apoiadas em rede: o caso da incubadora de empresas de base tecnológica da Universidade Federal Fluminense. Organização \& Estratégia, 4(1), 71-90.

Ries, E. (2012a). Él método Lean Startup: Cómo crear empresas de éxito utilizando la innovación continua. Editorial Desuto.

Ries, E. (2012b). A Startup Enxuta. São Paulo: Leya.

Rizzi, D. I., Wescinski; J. V., Poli, O., \& Jacoski, C. A. (2017). The importance of incubation processes from the perspective of incubated and graduated companies. Journal of Information Systems and Technology Management, 14(2), 263-279.

Rocha, R. O., Olave, M. E. L., \& Ordonez, E. D. M. (2020). Estratégias de Inovação: Uma Análise em 'Startups' de Tecnologia da Informação. Revista de Empreendedorismo e Gestão de Pequenas Empresas, 9(3), 237-271.

Santos, V., Beuren, I. M., \& Conte, A. (2017). Uso de instrumentos do sistema de controle gerencial em empresas incubadas. Contabilidade Vista \& Revista, 28(3), 103-132. 
Sebrae, Serviço Brasileiro de Apoio às Micro e Pequenas Empresas. (2014). Empreendedorismo: Startups. Recuperado de: https://www.sebrae.com.br/sites/PortalSebrae/artigos/o-que-e-umastartup,6979b2a178c83410VgnVCM1000003b74010aRCRD. Acesso em: 08 nov. 2019.

Sebrae, Serviço Brasileiro de Apoio às Micro e Pequenas Empresas. (2017). Biblioteca digital: $O$ que é uma startup? Recuperado de: https://www.sebraemg.com.br/atendimento/bibliotecadigital/documento/texto/o-quee-uma-empresa-startup. Acesso em: 08 nov. 2019.

Sebrae, Serviço Brasileiro de Apoio às Micro e Pequenas Empresas. (2019). Leis. Recuperado de: http://www.sebraesc.com.br/leis/default.asp?vcdtexto=4823\&\%5E\%5E. Acesso em: 14 nov. 2019.

Silva, E. E., Krakauer, P. V. C., \& Coda, R. (2020). Empresas 'Startups': Análise do Ciclo de Vida a partir do Modelo de Lester, Parnell e Carraher. Revista IberoAmericana de Estratégia, 19(1), 81-103.

Stoilov, I. A. (2015). Innovation in technological start-ups: Korean start-up ecosystem. Universitat Autonoma de Barcelona. Degree: Business Administration and Management. Recuperado de: https://pdfs.semanticscholar.org/820b/422d8577c64371e83bce38a0de709cf57353.p df. Acesso em: 06 fev. 2020.

Storopoli, J. E., Binder, M. P., \& Maccari, E. A. (2013). Incubadoras de empresas e o desenvolvimento de capacidades em empresas incubadas. Revista de Ciências da Administração, 15(35), 36-51.

Torres, N. N. de J., \& Souza, C. R. B. (2016). Uma Revisão da literatura sobre Ecossistemas de Startups de Tecnologia. Brazilian Symposium on Information Systems, Florianópolis, SC, 12. SBC, 385-392.

Data de Submissão: 05/11/2020

Data de Aceite: 09/04/2021 